\title{
Effect of Ultrasound on Chromosomes of Lymphocyte Cultures
}

\author{
USAMA ABDULLA， DAVID TALBERT, MARY LUCAS, MARY MULLARKEY
}

British Medical fournal, 1972, 3, 797-799

\section{Summary}

In-vitro experiments have been undertaken to assess the effect of ultrasound at diagnostic and therapeutic levels on chromosomes of human lymphocyte cultures. The frequency used was about $2 \mathrm{MHz}$. The intensity was that of diagnostic level, $23 \mathrm{~mW} / \mathrm{cm}^{2}$, which was increased stepwise to $3.5 \mathrm{~W} / \mathrm{cm}^{2}$. The time of exposure varied from two to eight hours. No difference could be detected between the numbers of cells with aberrations in the insonated and control cultures, but aggregation of red cells was observed at high intensities.

\section{Introduction}

Since the introduction of ultrasound into medicine about 15 years ago, and with the use of various techniques, concern has been expressed about its safety. While it has been suggested that diagnostic levels of ultrasound can cause chromosome damage (Macintosh and Davey, 1970, 1972) this has not been substantiated by recent experimental work (Bobrow et al., 1971; Boyd et al., 1971; Coakley et al., 1971, 1972; Bleaney et al., 1972; Buckton and Baker, 1972; Hill et al., 1972; Watts et al., 1972).

We have studied the effect of diagnostic ultrasound in vivo on maternal and fetal chromosomes and observed no increase in the number of chromosome aberrations in blood cultures from insonated mothers and babies when compared with controls (Abdulla et al., 1971).

In the present experiments cells were studied after long exposures to intensities of continuous-wave ultrasound similar to those produced by present diagnostic and therapeutic equipment.

\section{Methods}

\section{EXPERIMENTAL}

Since many of the problems of evaluating some of the previous work in this field spring from uncertainties about the exact experimental conditions used, care was taken to establish and measure these conditions for both the insonated and the control specimens. Accordingly the control and test samples were in the same type and batch of culture tubes and in the same waterbath.

The test tank specially constructed for the purpose (Fig. 1) is a rectangular Perspex box with a sound barrier (containing an air space) down the centre. The two polystyrene culture tubes are supported on either side of this barrier. At each end of the barrier, on the control side, sonic baffles allow water to circulate

\footnotetext{
Institute of Obstetrics and Gynaecology, Queen Charlotte's Maternity Hospital, London W.6

USAMA ABDULLA, M.R.C.o.G., Senior Registrar (Present appointment: Lecturer, Oxford University, Nuffield Department of Obstetrics and Gynaecology, John Radcliffe Hospital, Oxford)

DAVID TALBERT, B.SC., Physicist

Galton Laboratory, University College, London N.W.1

MARY LUCAS, M.B., B.S, Lecturer

MARY MULLARKEY, B.SC., Technician
}

but reject sound to a level less than one-thousandth of that in the test beam. On the test side the specially constructed transducer produces an ultrasonic beam of circular cross-section about $1 \mathrm{~cm}$ in diameter. The frequency used was about $2 \mathrm{MHz}$, and so diffraction effects were present. The sound intensity pattern at various points in the tank was plotted by using a miniature hydrophone constructed from a $1-\mathrm{mm}$-wide chip of

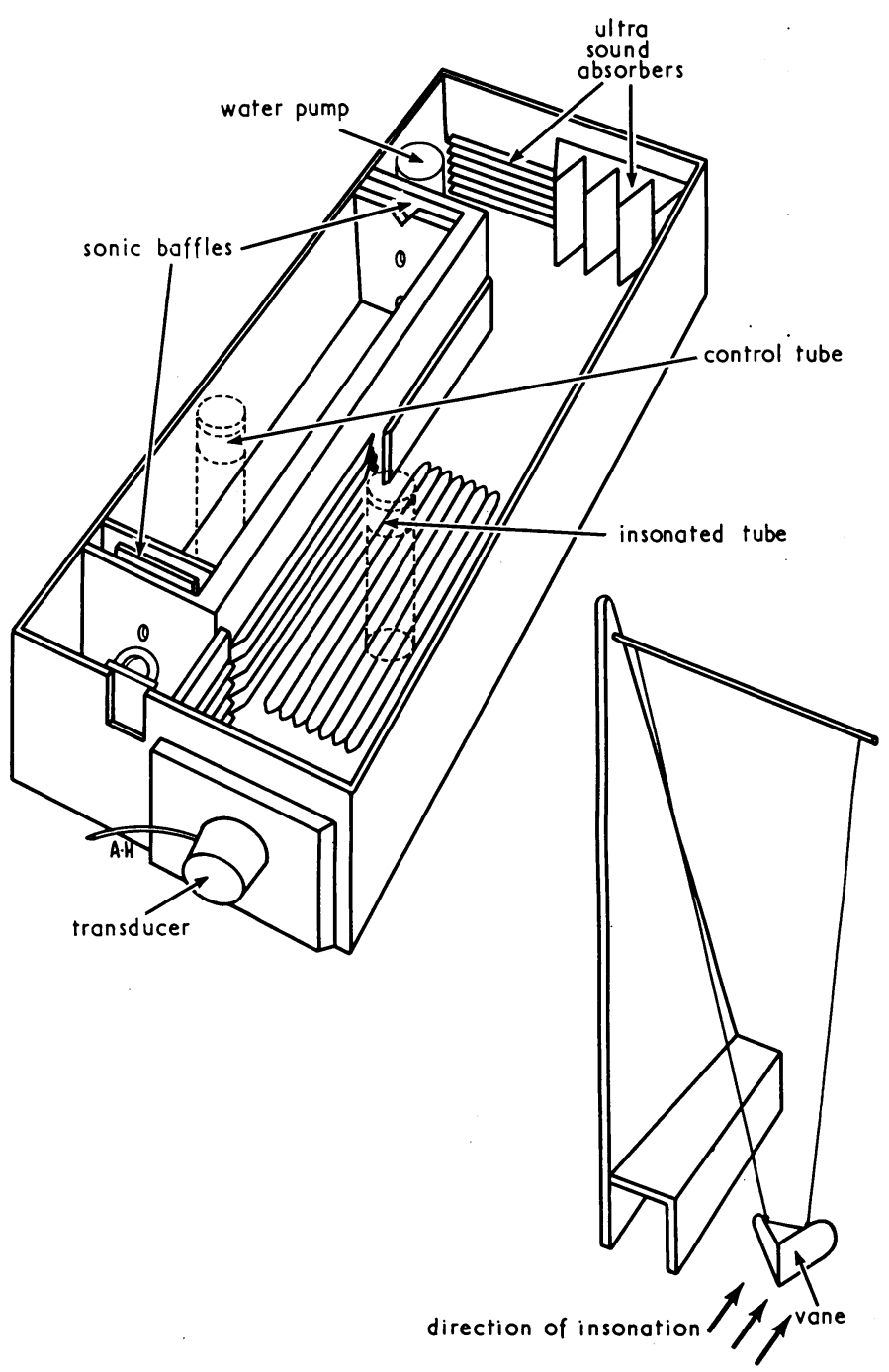

FIG. 1-Left: Insonation tank. Right: Sonic pressure measuring vane.

the same material as the transducer. A position for the test cell was chosen just beyond the Fresnel zone giving uniform intensity over about $1 \mathrm{~cm}$ diameter.

The far end of the tank and its walls and bottom were lined with silicon rubber (Midland Silicones Silestomer 9160 and 9161 mixed) sound absorbent wedges so that $99 \%$ of incident sound was absorbed during the multiple reflections between wedge focus before emerging back into the tank.

The beam power was measured by hanging a split $45^{\circ}$ reflector (Fig. 1) in the path of the beam at the point to be measured and noting the distance it was deflected. From its weight in water and the measured length of its suspension the 
sound radiation pressure was calculated as an absolute quantity. From the projected area of interception of the beam an average power per unit area was calculated. The hydrophone used was then placed in the same position and calibrated.

The intensity of ultrasound inside the sample tube was plotted with the calibrated hydrophone, and it was found that though the beam was deflected from the outer region of the tube the central intensity was about equal to that incident. There was some evidence of about $10 \%$ reflection from the rear of the tube which, while not enough to provide true standing waves, made up the transmission loss through the front of the tube to produce this approximate equality. Before each test run the average beam power was checked with the pressure vane in the position to be occupied by the test tube. Thereafter the input power to the crystal was monitored. The circulating water which couples the ultrasound was held at $36^{\circ} \mathrm{C}$ to ensure that any heat generated in the test tube by absorption would not cause its temperature to rise above $37^{\circ} \mathrm{C}$. Although the $36^{\circ} \mathrm{C}$ was maintained by a thermostat system it was monitored by a clinical thermometer to record any excess temperature.

\section{CYTOGENIC METHODS}

Peripheral blood cultures were set up from three healthy donors by using a slight modification of the method in use in this laboratory. These cultures are usually set up in $4 \mathrm{ml}$ of culture medium and $1 \mathrm{ml}$ of serum. The beam of ultrasound did not extend over this volume, so to insure that all the cells were insonated $2 \mathrm{ml}$ of medium was used. For each experiment two cultures from the same donor were set up in polystyrene tubes and both placed in the water-bath. One was shielded and acted as a control and the other was exposed to ultrasound. After insonation $2 \mathrm{ml}$ of warmed medium was added to each bottle and they were incubated at $37^{\circ} \mathrm{C}$.

Accurate assessment of the effect of any treatment on the type and number of aberrations can be made only if the cells are examined in the first mitosis after exposure (U.N. Scientific Committee, 1969; Evans, 1970). The total culture time including the period of insonation was therefore 52-54 hours. Demecolcine (Colcemid) was added for the last two hours of culture. Air-dried chromosome preparations were made after the usual hypotonic treatment and fixation in alcohol-acetic acid. The slides were coded and examined by two observers, who scored the cells for aberrations as previously described (Abdulla et al., 1971).

\section{Results}

No attempt was made to measure the mitotic rate, but no difference could be detected between the rates of test and control slides when they were being searched for well-spread mitoses. The cultures failed to grow several times but each time both test and control cultures were failures.

The intensity of the ultrasound and the length of time of exposure are shown in the Table together with the types and frequencies of the aberrations found. No significant differences either in the types or the frequencies of aberrations could be detected between the test and control cultures.

When the tubes were removed from the water bath after two hours' insonation at $2 \mathrm{~W}$ intensity clumping of the cells was observed in the test cultures (Fig. 2). Clumping could be seen after 30 minutes' insonation at $3.5 \mathrm{~W}$ intensity and was pronounced after an hour. The clumps could be dispersed easily by gently inverting the tube. Some cells were pipetted gently on to a slide and the wet preparation was examined under low magnification $(\times 160)$.

Phytohaemagglutinin causes agglutination of red cells which was visible microscopically, but no difference could be seen between insonated and control cultures. This effect of phytohaemagglutinin might have contributed to the clumping seen after insonation so tubes were set up without it. After insonation at $3.5 \mathrm{~W}$ for 30 minutes clumping could be seen and was very prominent after one-and-three-quarter hours. This clumping gradually becomes more marked until all the cells have fallen to the bottom or are clumped on the side of the tube, so that there is no definite point at which it could be said to be definitely absent, present, or complete. When phytohaemagglutinin had not been added the clumps were so easily broken up by pipetting on to a slide that they could not be observed under the microscope. This finding suggested that the cell membrane had not been permanently damaged and that ultrasound might have such an effect on any particles suspended in a liquid. Kaolin particles suspended in water showed pronounced clumping after one hour's insonation at $3.5 \mathrm{~W}$ (Fig. 3).

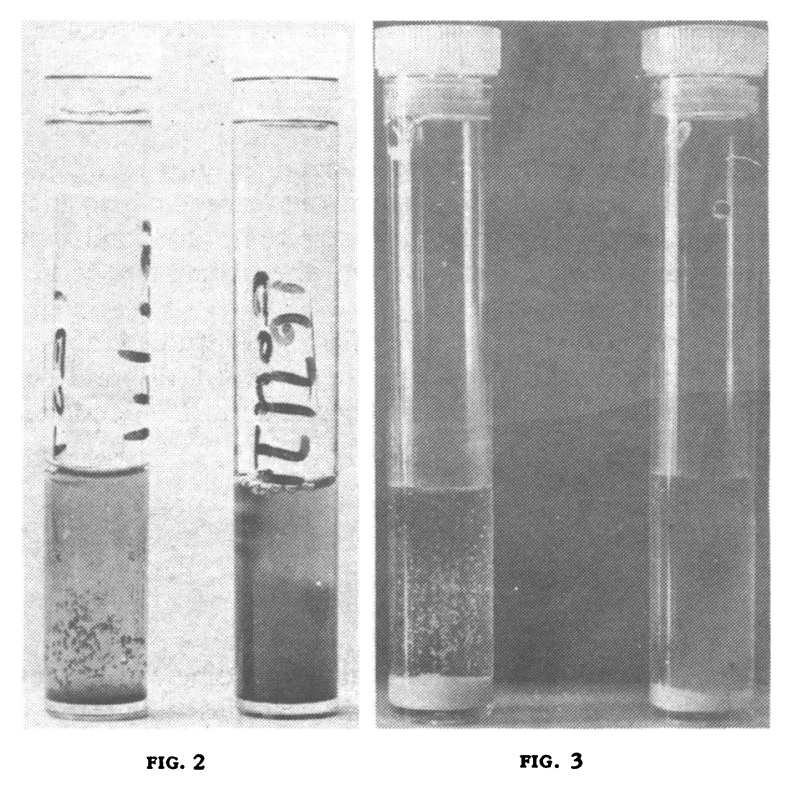

FIG. 2-Left: Clumping of red cells in test culture after two hours' insonation at $2 \mathrm{~W} / \mathrm{cm}^{2}$. Right: Control sample.

FIG. 3-Left: Clumping of kaolin particles in water after one hour's insonation at $3.5 \mathrm{~W} / \mathrm{cm}^{2}$. Right: Control sample.

Numbers of Chromosome Aberrations in Control and Insonated Cultures

\begin{tabular}{|c|c|c|c|c|c|c|c|c|c|c|c|c|c|}
\hline \multirow{3}{*}{$\begin{array}{l}\text { Ultrasound } \\
\text { Intensity }\end{array}$} & \multirow{3}{*}{$\begin{array}{l}\text { Insonation } \\
\text { Time } \\
\text { (Hours) }\end{array}$} & \multicolumn{7}{|c|}{ No. of Cells Tested } & \multirow{3}{*}{$\begin{array}{c}\text { Chromatid } \\
\text { Gaps }\end{array}$} & \multirow{3}{*}{$\underset{\text { Breaks }}{\text { Chromatid }}$} & \multirow{3}{*}{$\begin{array}{c}\text { Iso- } \\
\text { chromatid } \\
\text { Gaps }\end{array}$} & \multirow{3}{*}{$\begin{array}{c}\text { Iso- } \\
\text { chromatid } \\
\text { Breaks }\end{array}$} & \multirow{3}{*}{$\begin{array}{c}\text { Total } \\
\text { Cells } \\
\text { with } \\
\text { Aber- } \\
\text { rations }\end{array}$} \\
\hline & & & & & oson & & & & & & & & \\
\hline & & $<44$ & 44 & 45 & 46 & 47 & 48 & $>48$ & & & & & \\
\hline 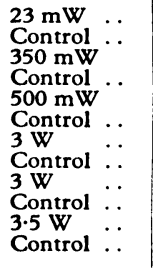 & $\begin{array}{ll}2 & \{ \\
2 & \{ \\
2 & \{ \\
2 & \{ \\
5 & \{\end{array}$ & $\begin{array}{l}1 \\
0 \\
2 \\
2 \\
4 \\
6 \\
4 \\
1 \\
7 \\
6 \\
0 \\
1\end{array}$ & $\begin{array}{l}1 \\
1 \\
1 \\
0 \\
2 \\
5 \\
1 \\
0 \\
1 \\
1 \\
1 \\
0\end{array}$ & $\begin{array}{r}5 \\
7 \\
3 \\
8 \\
9 \\
7 \\
1 \\
5 \\
9 \\
12 \\
1 \\
3\end{array}$ & $\begin{array}{l}93 \\
92 \\
93 \\
90 \\
85 \\
81 \\
94 \\
93 \\
82 \\
77 \\
96 \\
94\end{array}$ & $\begin{array}{l}0 \\
0 \\
1 \\
0 \\
0 \\
1 \\
0 \\
1 \\
0 \\
3 \\
2 \\
2\end{array}$ & $\begin{array}{l}0 \\
0 \\
0 \\
0 \\
0 \\
0 \\
0 \\
0 \\
0 \\
1 \\
0 \\
0\end{array}$ & $\begin{array}{l}0 \\
0 \\
0 \\
0 \\
0 \\
0 \\
0 \\
0 \\
1 \\
0 \\
0 \\
0\end{array}$ & $\begin{array}{l}3 \\
3 \\
3 \\
3 \\
1 \\
1 \\
3 \\
3 \\
2 \\
3 \\
3 \\
1\end{array}$ & $\begin{array}{l}0 \\
0 \\
0 \\
0 \\
0 \\
0 \\
3 \\
1 \\
0 \\
3 \\
1 \\
0\end{array}$ & $\begin{array}{l}0 \\
0 \\
0 \\
0 \\
0 \\
0 \\
0 \\
0 \\
0 \\
0 \\
0 \\
1\end{array}$ & $\begin{array}{l}0 \\
0 \\
0 \\
0 \\
0 \\
1 \\
0 \\
1 \\
0 \\
0 \\
2 \\
4\end{array}$ & $\begin{array}{l}3 \\
3 \\
2 \\
3 \\
1 \\
2 \\
6 \\
5 \\
2 \\
6 \\
6 \\
5\end{array}$ \\
\hline
\end{tabular}




\section{Discussion}

Although some workers (Macintosh and Davey, 1970, 1972) have reported chromosome damage after in-vitro exposure of cells to diagnostic levels of ultrasound, their findings have not been reproduced by others (Bobrow et al., 1971; Boyd et al., 1971 ; Buckton and Baker 1972; Watts et al., 1972). In the present study chromosome damage could not be detected after eight hours' exposure to ultrasound at $3.5 \mathrm{~W} / \mathrm{cm}^{2}$, which is similar to intensities produced by some therapeutic equipment. Others (Coakley et al., 1971, 1972) have used very high pulsed power levels for shorter periods without observing significant chromosomal aberrations.

It seems probable from our in-vitro experiments and other in-vivo studies (Abdulla et al., 1971; Lucas et al., 1972) that chromosome damage is not caused by ultrasound when used as a diagnostic tool.

There is, however, evidence of another factor that might cause damage in other ways. Clumping of red cells was seen in this study, and aggregation of red cells with stasis of blood flow has been shown to occur in blood vessels of chick embryos (Dyson et al., 1971). If stasis occurs in a fetal blood vessel the interruption to blood flow could damage the rapidly developing tissues.

We therefore conclude that other factors may well set a safety limit to ultrasonic power level below that at which chromosomal damage occurs and that absence of such damage should not be relied on too heavily as a measure of safety. (Taylor and Pond, 1972).

We wish to thank Professor C. J. Dewhurst for his interest and encouragement. Also we are grateful for the help of Sonicaid Limited and the Department of Health and Social Security, who made this study possible.

Requests for reprints should be addressed to Dr. U. Abdulla, Nuffield Department of Obstetrics and Gynaecology, John Radcliffe Hospital, Oxford OX3 9DU.

\section{References}

Abdulla, U., et al. (1971). Lancet, 2, 829.

Bleaney, B. I., Blackbourn, P., and Kirkley, J. (1972). British fournal of

Radiology, 45, 354.
Bobrow, M., Blackwell, N., Unrau, A. E., and Bleaney, B. (1971). Fournal of Obstetrics and Gynaecology of the British Commonwealth, 78, 730.

Boyd, E., et al. (1971). British Medical fournal, 2, 501.

Buckton, K. E., and Baker, N. V. (1972). British fournal of Radiology, 45,

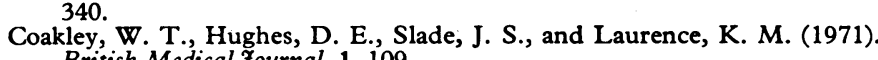
British Medical fournal, 1, 109.

Coakley, W. T., Slade, J. S., and Braeman, T. M. (1972). British fournal of Radiology, 45, 328

Dyson, M., Woodward, B., and Pond, J. B. (1971). Nature, 232, 572.

Evans, H. J. (1970). In Human Population Cytogenetics, ed. P. A. Jacobs, p. 191. Edinburgh, University Press.

Hill, C. R., Joshi, G. P., and Revell, S. H. (1972). British fournal of Radiology, 45,333 .

Lucas, M., Mullarkey, M., and Abdulla, U. (1972). British Medical fournal,

Macintosh, I. J. C., and Davey, D. A. (1970). British Medical Fournal, 3, 92. Macintosh, I. J. C., and Davey, D. A. (1972). British fournal of Radiology,

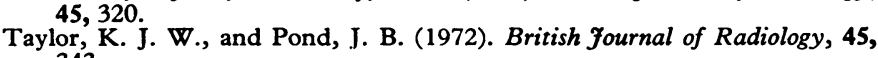
343.

United Nations Scientific Committee (1969). Report on the Effects of Atomic Radiation. New York, United Nations.

Watts, P. L., Hall, A.J., and Fleming, J.E.E. (1972) British fournal of Radio$\log y, 45,354$

\title{
Placental Lactogen Levels as Guide to Outcome of Threatened Abortion
}

\author{
P. A. R. NIVEN, J. LANDON, T. CHARD
}

British Medical fournal, 1972, 3, 799-801

\section{Summary}

The clinical value has been assessed of circulating placental lactogen levels as a pointer to the outcome in a patient with vaginal bleeding in early pregnancy. By using a semiautomated radioimmunoassay the normal range of values for the first and second trimesters has been established. In patients admitted with vaginal bleeding after the eighth week of gestation estimation of plasma human placental lactogen showed that patients with low levels were those in whom the abortion was completed during the first admission. Women whose pregnancies continued normally or who aborted after their first discharge from hospital had normal levels. In a small group sampled before the onset of bleeding but who later aborted the mean levels were lower than normal. This simple and inexpensive test can indicate those women in whom abortion is inevitable and could be used to reduce substantially the length of hospital stay in this common complication of early pregnancy.

\section{Introduction}

It is estimated that one in every seven pregnancies ends in abortion, and most such patients require hospital admission.

Departments of Obstetrics and Gynaecology and Chemical Pathology, St. Bartholomew's Hospital, London E.C.1

P. A. R. NIVEN, F.R.C.S., M.R.C.o.G., Senior Registrar

J. LANDON, M.D., Professor

T. CHARD, M.D., M.R.C.o.G., Senior Lecturer
In addition many women are admitted with vaginal bleeding in early pregnancy who achieve a successful outcome. On clinical grounds it is frequently impossible to distinguish between those pregnancies which are doomed and those which will proceed to fruition, and the diagnosis may be apparent only after several days' occupancy of an expensive hospital bed. A number of tests have been described which may help to make this important distinction, including the determination of plasma levels of human placental lactogen (Genazzani et al., 1969, 1971; Saxena et al., 1969; Singer et al., 1970; Haour et al., 1971; Spona and Janisch, 1971). These previous studies were based on relatively small numbers of patients and samples, and detailed analysis of results in relation to fetal outcome and normal levels was not presented.

The present study was undertaken to establish the normal range of circulating human placental lactogen levels during the first two trimesters and, based on these data, to assess the prognostic value of human placental lactogen determinations in patients with vaginal bleeding of sufficient severity to necessitate admission to hospital.

\section{Subjects and Methods}

The normal range was based on 736 samples from 634 singleton pregnancies of certain dates and compatible uterine enlargement in which no abnormality occurred before the $28: h$ week of gestation.

A total of 422 samples were collected from 236 cases of bleeding in early pregnancy. This group included 141 subjects who aborted during their first admission, 14 who aborted 